\title{
WISER Assessment: A Communication Program Assessment Framework
}

\author{
Michael G. Strawser $\bullet$ \\ Lindsay Neuberger $\odot$
}

Keywords: learning outcome assessment, instructional communication, pedagogy, WISER, communication education

\begin{abstract}
Learning outcome assessment is a fairly recent trend in higher education that began in the 1980s (Lubinescu et al., 2001). Today, many faculty perceive assessment reporting to be tedious, time-consuming, and irrelevant busywork (Wang \& Hurley, 2012). Unfortunately, this systematic process created to use empirical evidence to measure, document, and improve student learning has in many cases lost sight of this central goal. As a result, faculty may be justified in their opinions about it. This essay proposes a framework for addressing this thorny issue via WISER. WISER is an acronym for five content pillars of the communication discipline faculty can use to ensure their assessment efforts achieve the goal of not only documenting but also improving student learning. WISER stands for writing, immersive experiences, speaking, ethical communication, and research as programmatic assessment categories. These WISER categories extend the National Communication Association (NCA)-endorsed domains of communication learning in ways that make them functional for assessment.
\end{abstract}

Laments about the current state of university assessment are widespread and usually discouraging (Gilbert, 2019). Many faculty perceive assessment reporting to be tedious, time-consuming, and irrelevant busywork (Wang \& Hurley, 2012). Such dissatisfaction has been a pervasive issue in the academy for decades. As Wergin (1999) wrote over 30 years ago, "most faculty failed to see the relevance of program evaluation and assessment" and perceived it to be "ritualistic, "time-consuming, "mandated from above," and having few real benefits for faculty students, or programs (para. 5). It appears such 
negative perceptions have grown stronger as reflected in Gilbert's claim that assessment is an enormous waste of time.

Some research suggests that these perceptions may be due in part to lack of faculty understanding of and involvement in assessment processes (Lederman, 2010). When faculty fail to see the relevance of a task, as well as training in how to perform it well (Holmboe et al., 2011), it follows that they are unlikely to support or become involved willingly with it (Grunwald \& Peterson, 2003). Moreover, when the requests made by universities and accreditation agencies appear unnecessarily cumbersome, faculty will be further demotivated to participate.

Some research points to faculty development as a means to address these challenges. Wehlburg (2008), for instance, proposes an integrated and transformative assessment model where faculty are embedded in the process and empowered to own their program assessment rather than asked to respond to external mandates that amount to checking the boxes. Other research suggests doing so involves creating a culture of assessment (e.g., Farkas, 2013; Ndoye \& Parker, 2010; Weiner, 2009). Central to doing so is to build assessment programs and processes from the ground up so to speak. When faculty realize the value of assessment and learn how to do so effectively, they are more likely to be motivated to be involved in the process (Bresciani, 2011). More specifically, they will build on departmental initiatives, address real problems, enhance student learning, and make good use of time and resources (Walvoord, 2010), as well as identify clear goals, measures, and rubrics (Charlesworth, 2010). Ultimately, the goal of assessment should be on continuous improvement through self-evaluation (Backlund et al., 2010).

Communication departments are not immune to these challenges. Thus, we propose the WISER framework as a means to begin building a culture of assessment among communication department faculty. Because these pillars are grounded in NCA's domains of communication learning, we believe faculty will perceive them as a relevant place to begin. Ultimately, program learning outcome assessment based on these NCA-endorsed pillars will enhance legitimacy among external reviewers that may be asked to evaluate our programs for accreditation purposes.

Based on reasons discussed in more depth throughout this essay, we believe that though programmatic assessment can be a thorny problem in communication pedagogy, the WISER framework may be an effective foundation on which to build faculty-driven communication assessment plans and processes.

\section{Assessment in the Communication Discipline}

Disciplinary differences in assessment do matter (Jessop \& Maleckar, 2014). For communication assessment, student learning may be measured via cognition, affect, and behavior (Bloom, 1956) and related to the principles of communication competence in a given communication content domain. More specifically, McCroskey (1982) established the domains of communication learning as affect (feelings, attitudes, motivations, and willingness to communicate), behavior (abilities to perform certain communication skills/behaviors), and cognition (knowledge or understanding of communication content, theories, and principles). McCroskey posits further that one can be competent in one or two domains; however, effective learning is measured via competence in all three domains simultaneously.

Other descriptions for measuring student competence in communication exist (for instance, Littlejohn \& Jabusch, 1982; Morreale et al., 1993; Spitzberg, 2007). The critical point we are making is not about which one to use but, rather, to make sure there is a connection between the domains of communication 
learning, the dynamics of communication competence, and the measures of learning outcome achievement.

But, practically, what might these relationships look like? To help answer this question in 2015, Spectra, the National Communication Association (NCA) magazine, published an entire edition devoted to developing and implementing learning outcomes in the communication discipline. The Spectra volume presented a holistic perspective on what communication graduates should know, understand, and do. One article provided an overview of NCA's Learning Outcomes in Communication (LOC) and outlined nine proposed outcomes (National Communication Association, 2015). These guidelines serve as an essential outline to discuss meaningful assessment work in our discipline. The nine general outcomes include:

1. Describe the communication discipline and its central questions

2. Employ communication theories, perspectives, principles, and concepts

3. Engage in communication inquiry

4. Create messages appropriate to the audience, purpose, and context

5. Critically analyze messages

6. Demonstrate the ability to accomplish communicative goals

7. Apply ethical communication principles and practices

8. Utilize communication to embrace difference

9. Influence public discourse

NCA positions one central assumption about the outcomes; communication constructs the social world and is relational, collaborative, strategic, symbolic, and adaptive (National Communication Association, 2015). Although the list of outcomes above is long, it is not necessarily exhaustive (National Communication Association, 2015). They do serve, however, as a foundation for ongoing conversations about how we might think strategically about improving student learning as it relates specifically to communication.

While useful for a starting point for assessment, more refinement is necessary for them to serve as a useful framework for conducting assessment (Bresciani, 2011). Ultimately, we agree with Allen (2004), that assessment should be meaningful, manageable, sustainable, and faculty-led. The WISER communication-centric assessment framework was, in fact, developed and refined by communication faculty. Moreover, WISER is practical, relevant, and appropriately brief (Walvoord, 2010). The elements are comprehensible and general enough to be measurable across a variety of communication disciplines ranging from Advertising and Public Relations to Media Studies to Journalism to Human Communication. 


\section{WISER}

Based on the NCA communication learning domains, students graduating with a communication degree should demonstrate strong Writing skills, have completed Immersive learning experiences, be prepared to Speak effectively, conduct themselves Ethically, and be able to conduct Research. We believe what we have developed could serve as a model for other programs and departments seeking to refine and simplify their communication program assessment processes.

One useful source for assessing the utility of WISER is the Association of American Colleges \& Universities (AAC\&U) Valid Assessment of Learning in Undergraduate Education (VALUE) rubrics (AAC\&U, 2009). In partnership with faculty representing colleges and universities across the country, the AAC\&U developed VALUE rubrics to identify essential learning outcomes and identify basic frameworks of expectations for student learning across disciplines (Rhodes, 2010). The focus areas of these rubrics are intellectual and practical skills (e.g., critical thinking, written communication, information literacy), personal and social responsibility (e.g., global learning and ethical reasoning), and integrative and applied learning (e.g., integrative learning). The rubrics can be modified for application or adopted in whole and can provide a strong starting point for assessment (AAC\&U, 2009). All the WISER categories have a VALUE Rubric counterpart and while it is not necessary to use the VALUE rubric to address the corresponding competency, it can be helpful. Our WISER acronym is described in more detail below.

\section{Writing}

We believe our graduates should be strong writers in their individual area of communication specialization. Written communication is a core VALUE rubric outlined by the AAC\&U (2009) and represents successful development and expression of ideas in writing many genres and styles. Moreover, the National Association of Colleges and Employers (NACE, 2018) lists written communication skills as the top attribute employers seek from job candidates. Finally, one of the National Communication Association's (NCA) key learning outcomes is to create messages appropriate to the audience, purpose, and context.

\section{Immersion}

We believe students should engage in real-world learning experiences such as internships, study abroad, and service learning. Integrative learning, or the idea that curricular learning across courses and co-curricular experiences outside the classroom combine to allow for learning transfer to contexts beyond campus, is another core VALUE rubric outlined by the AAC\&U (2009). Learning does not only take place in the classroom (Sellnow et al., 2015). Immersive experiences in local communities and global contexts provide essential opportunities for students to apply communication theory and skills in real-world contexts beyond the academy.

\section{Speaking}

We believe our graduates should have strong oral communication skills that manifest through varying speech types and rhetorical contexts. Oral communication is also a core VALUE rubric outlined by the AAC\&U (2009) and is considered an essential attribute by $67.4 \%$ of employers (NACE, 2018), as well as in the key NCA learning outcomes. 


\section{Ethics}

We believe our students should conduct themselves according to the highest ethical standards as have been presented through professional entities such as the National Communication Association. In fact, several key learning outcomes proposed by NCA focus on principles of communication ethics (e.g., create messages appropriate to the audience, purpose, and context; apply ethical communication principles and practices; utilize communication to embrace difference). Ethical Reasoning is also a core VALUE rubric outlined by the AAC\&U (2009), which focuses on reasoning about right and wrong across diverse settings and social contexts.

\section{Research}

Finally, we believe our graduates should use critical thinking skills to identify and examine possible answers to their questions about communication phenomena. Inquiry and analysis, which clearly represents research, is a core VALUE rubric outlined by the AAC\&U (2009) and is embedded in core learning outcomes proposed by the NCA (e.g., employ communication theories, perspectives, principles, and concepts; engage in communication inquiry; create messages appropriate to the audience, purpose, and context; critically analyze messages).

\section{Application Across Communication Subfields}

We believe these WISER pillars are particularly useful in terms of their broad applicability across the Communication discipline. That is, these core components can be used to assess diverse programs including Advertising, Journalism, Public Relations, and Radio/Television. Essential in that broad application is the ability to operationalize assessment differently across disciplines. For example, demonstration of research skills in a Communication course may focus on constructing a survey about communication phenomena and analyzing data, while Journalism student success in research may be more focused on interviewing skills. There are also very clear ethical guidelines that may be important to assess for Advertising students, whereas Radio/Television students may be guided by a distinct set of professional ethical guidelines. This malleability and broad applicability is a strength of the WISER assessment framework. Thus, the WISER framework can be transferred across specialty areas because it does not dig down into operationalization but focuses on the broader areas of importance while allowing for distinct measurement protocols. Further, allowing for distinct disciplinary operationalization also empowers faculty to guide their own program assessment while being unified across majors in a school or college of communication.

\section{Discussion: Operationalizing the WISER Framework}

Metacognition, or the ability to reflect critically on educational experiences is essential to build robust knowledge and effectively prepare students for life beyond the classroom (Winne \& Azevedo, 2014). In that sense, the WISER pillars are also learner-centered in that they afford students meaningfully ways to engage in reflection on their own learning and its applicability to their personal and professional lives. By integrating discussion of the WISER pillars into several courses, students are encouraged to not only identify, but also articulate skills learned in their Communication courses.

WISER is also valuable because it streamlines NCA's communication learning outcomes and competency models (see Table 1). 


\begin{tabular}{|c|c|c|c|}
\hline \multicolumn{4}{|c|}{$\begin{array}{l}\text { TABLE } 1 \\
\text { Connecting WISER to NCA Learning Outcomes, Domains of Communication Learning, and Assessment } \\
\text { Measures }\end{array}$} \\
\hline WISER Pillar & $\begin{array}{l}\text { NCA Learning } \\
\text { Outcomes }\end{array}$ & $\begin{array}{l}\text { McCroskey: Domains of Communication } \\
\text { Learning }\end{array}$ & $\begin{array}{l}\text { Potential Assessment } \\
\text { Measures }\end{array}$ \\
\hline Writing & $\begin{array}{l}\text { Create messages } \\
\text { appropriate to the } \\
\text { audience, purpose, } \\
\text { and context; } \\
\text { Demonstrate the } \\
\text { ability to accomplish } \\
\text { communicative goals; } \\
\text { Influence public } \\
\text { discourse }\end{array}$ & $\begin{array}{l}\text { How have student perceptions about } \\
\text { writing changed during their academic } \\
\text { communication program experience? } \\
\text { Have student writing skills become } \\
\text { more effective during their academic } \\
\text { communication program experience? } \\
\text { Has student knowledge or understanding } \\
\text { about writing increased during their } \\
\text { academic communication program } \\
\text { experience? }\end{array}$ & $\begin{array}{l}\text { Written Communication } \\
\text { Value Rubric }\end{array}$ \\
\hline $\begin{array}{l}\text { Immersive } \\
\text { Experiences }\end{array}$ & $\begin{array}{l}\text { Employ } \\
\text { communication } \\
\text { theories, perspectives, } \\
\text { principles, and } \\
\text { concepts; } \\
\text { Influence public } \\
\text { discourse; } \\
\text { Demonstrate the } \\
\text { ability to accomplish } \\
\text { communicative goals }\end{array}$ & $\begin{array}{l}\text { How have student perceptions about } \\
\text { immersive experiences changed during } \\
\text { their academic communication program } \\
\text { experience? } \\
\text { Have students become more effective } \\
\text { communicators as a result of their immersive } \\
\text { experiences? } \\
\text { Has the collective communication } \\
\text { competence of our students increased as } \\
\text { a result of their participation in immersive } \\
\text { experiences? }\end{array}$ & $\begin{array}{l}\text { Integrative Learning Value } \\
\text { Rubric }\end{array}$ \\
\hline Speaking & $\begin{array}{l}\text { Create messages } \\
\text { appropriate to the } \\
\text { audience, purpose, } \\
\text { and context; } \\
\text { Demonstrate the } \\
\text { ability to accomplish } \\
\text { communicative goals; } \\
\text { Influence public } \\
\text { discourse }\end{array}$ & $\begin{array}{l}\text { How have student perceptions about } \\
\text { speaking changed during their academic } \\
\text { communication program experience? } \\
\text { Have student speaking skills become } \\
\text { more effective during their academic } \\
\text { communication program experience? } \\
\text { Has student knowledge or understanding } \\
\text { about speaking increased during their } \\
\text { academic communication program } \\
\text { experience? }\end{array}$ & $\begin{array}{l}\text { Oral Communication Value } \\
\text { Rubric } \\
\text { NCA Competent Speaker } \\
\text { Evaluation Form }\end{array}$ \\
\hline Ethics & $\begin{array}{l}\text { Apply ethical } \\
\text { communication } \\
\text { principles and } \\
\text { practices; } \\
\text { Utilize communication } \\
\text { to embrace difference }\end{array}$ & $\begin{array}{l}\text { How have student perceptions about } \\
\text { communication ethics changed during } \\
\text { their academic communication program } \\
\text { experience? } \\
\text { Have students become more ethical } \\
\text { communicators as a result of their academic } \\
\text { communication program experience? } \\
\text { Has the collective knowledge of ethical } \\
\text { communication increased as a result of } \\
\text { their academic communication program } \\
\text { experience? }\end{array}$ & $\begin{array}{l}\text { Ethical Reasoning Value } \\
\text { Rubric }\end{array}$ \\
\hline
\end{tabular}




\begin{tabular}{|l|l|l|l|}
\hline Research & $\begin{array}{l}\text { Engage in } \\
\text { communication } \\
\text { inquiry; }\end{array}$ & $\begin{array}{l}\text { How have student perceptions about } \\
\text { research changed during their academic } \\
\text { communication program experience? } \\
\text { Critically analyze } \\
\text { messages }\end{array}$ & $\begin{array}{l}\text { Critical Thinking Value } \\
\text { Rubric } \\
\text { researchers as a result of their academic } \\
\text { communication program experience? } \\
\text { Has the collective knowledge of } \\
\text { communication inquiry increased as a result } \\
\text { of their academic communication program } \\
\text { experience? }\end{array}$ \\
\hline
\end{tabular}

\section{Robust and Transferable: A WISER Way}

Finally, we believe program administrators benefit from this WISER assessment framework because it can be implemented easily and effectively across diverse communication subfields. In fact, the school where the WISER framework was developed and initially implemented serves over 4,000 students across its majors. The WISER framework affords us an opportunity to measure student learning in flexible yet uniform ways, all of them related directly to the national standards adopted by the NCA. More specifically, Table 2 illustrates examples of courses that could be used to assess each pillar while Table 3 depicts how assignments in a given course might be used.

\section{TABLE 2}

Curriculum Map Using WISER Categories

\begin{tabular}{|l|l|l|l|l|l|}
\hline Pillar & Writing & Immersion & Speaking & Ethics & Research \\
\hline \multirow{3}{*}{ Course(s) } & $\begin{array}{l}\text { Intercultural, } \\
\text { Interpersonal, } \\
\text { Persuasion }\end{array}$ & $\begin{array}{l}\text { Internship, Study } \\
\text { Abroad, Indepen- } \\
\text { dent Study }\end{array}$ & $\begin{array}{l}\text { Advanced Public } \\
\text { Speaking, Group } \\
\text { Communication }\end{array}$ & $\begin{array}{l}\text { Research Meth- } \\
\text { ods, Advanced } \\
\text { Public Speaking }\end{array}$ & $\begin{array}{l}\text { Research Methods, } \\
\text { Public Communication } \\
\text { Campaigns }\end{array}$ \\
\hline
\end{tabular}

\section{TABLE 3}

Assignment Progression for WISER Implementation

\begin{tabular}{|l|l|l|l|}
\hline $\begin{array}{l}\text { Research Pillar-Public } \\
\text { Communication Cam- } \\
\text { paigns Course }\end{array}$ & $\begin{array}{l}\text { Research LO1: Develop } \\
\text { research questions and } \\
\text { hypotheses guided by } \\
\text { the literature }\end{array}$ & $\begin{array}{l}\text { Research LO2: Design } \\
\text { data collection protocols } \\
\text { and collect independent } \\
\text { data }\end{array}$ & $\begin{array}{l}\text { Research LO3: Draw } \\
\text { sound conclusions based } \\
\text { on data collected }\end{array}$ \\
\hline Assignment & $\begin{array}{l}\text { Campaign research ques- } \\
\text { tion/hypothesis assign- } \\
\text { ment }\end{array}$ & $\begin{array}{l}\text { Campaign data collection } \\
\text { assignment }\end{array}$ & $\begin{array}{l}\text { Campaign final paper } \\
\text { assignment }\end{array}$ \\
\hline
\end{tabular}

\section{Conclusion}

Program assessment can be difficult for many reasons. Moreover, when it is not faculty-driven by learning outcomes established in a given field, it can be perceived as "an enormous waste of time" (Gilbert, 2019). We propose WISER as an assessment framework for addressing this thorny issue in a variety of majors housed within the communication discipline. In Figure 1, we depict what we call "a WISER way" to develop and conduct meaningful program assessment. We also provide an Appendix that includes a 
sample demonstration of one WISER category. Specifically, we include an assignment description, a WISER assessment category that corresponds to the assignment description, a corresponding NCA learning outcome, and two rubric examples, the more in-depth value rubric, and the NCA competent speaker evaluation form. We hope these resources will be beneficial as tools to establish a more robust programmatic assessment mechanism. We believe this approach is a WISER way to create a positive culture of assessment that is efficient, meaningful, and designed for its ultimate purpose: to improve student learning.

\section{FIGURE 1}

A WISER Way

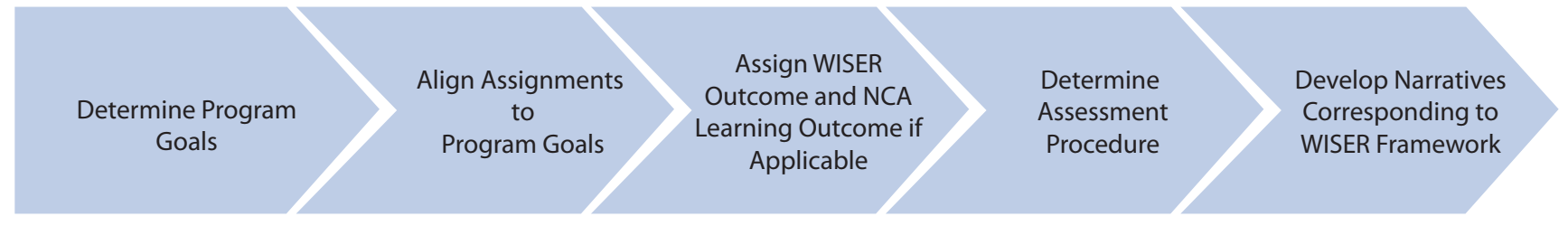

\section{References}

Allen, M. J. (2004). Assessing academic programs in higher education. Anker Publishing Company, Inc.

Association of American Colleges and Universities (AAC\&U). (2009). Inquiry and analysis VALUE rubric. https://web.archive.org/web/20200527175612/https://www.aacu.org/value/rubrics/inquiry-analysis

Backlund, P., Detwiler, T. J., Arneson, P., \& Danielson, M. A. (2010). Assessing communication knowledge, skills, and attitudes. In P. Backlund \& G. Wakefield (Eds.), A communication assessment primer (pp. 1-14). National Communication Association.

Bloom, B. S. (1956). Taxonomy of educational objectives: The classification of educational goals. Longmans, Green.

Bresciani, M. J. (2011). Identifying barriers in implementing outcomes-based assessment program review: A grounded theory analysis. Research and Practice in Assessment, 6, 5-16.

Charlesworth, D. (2010). Demystifying the programmatic review process: Ensuring quality control, fostering faculty development, and motivating faculty. In P. Backlund \& G. Wakefield (Eds.), A communication assessment primer (pp. 95-106). National Communication Association.

Farkas, M. G. (2013). Building and sustaining a culture of assessment: Best practices for change leadership. Reference Services review, 41(1), 13-31. http://dx.doi.org/10.1108/00907321311300857

Gilbert, E. (2019). Assessment is an enormous waste of time. The Chronicle of Higher Education. https://web.archive.org/web/20191226005947/https://www.chronicle.com/article/Assessment-Is-anEnormous/245937

Grunwald, H., \& Peterson, M. W. (2003). Factors that promote faculty involvement in and satisfaction with institutional and classroom student assessment. Research in Higher Education, 44, 173-204. https://doi.org/10.1023/A:1022051728874

Holmboe, E. S., Wad, D. S., Reznick, R. K., Katsufrakis, P. J., Leslie, K. M., Patel, V. L., Ray, D. D., \& Nelson, E. A. (2011). Faculty development in assessment: The missing link in competency-based medical education. Academic Medicine 86(4), 460-467. https://doi.org/10.1097/ACM.0b013e31820cb2a7

Jessop, T., \& Maleckar, B. (2014). The influence of disciplinary assessment patterns on student learning: A comparative study. Studies in Higher Education, 41, 696-711. http://dx.doi.org/10.1080/03075079. 2014.943170 
Lederman, D. (2010, May 28). The faculty role in assessment. https://web.archive.org/web/2020061714 4959/https://www.insidehighered.com/news/2010/05/28/faculty-role-assessment

Littlejohn, S. W., \& Jabusch, D. M. (1982). Communication competence: Model and application. Journal of Applied Communication Research, 10, 29-37. https://doi.org/10.1080/00909888209365210

Lubinescu, E. S., Ratcliff, J. L., \& Gaffney, M. A. (2001). Two continuums collide: Accreditation and assessment. New Directions for Higher Education, 2001(113), 5-21.

McCroskey, J. C. (1982). Communication competence and performance: A research and pedagogical perspective. Communication Education, 31, 1-7. https://doi.org/10.1080/03634528209384654

Morreale, S., Shockley-Zalabak, P., \& Whitney, P. (1993). The center of excellence in oral communication: Integrating communication across the curriculum. Communication Education, 42, 10-21. https://doi.org/10.1080/03634529309378909

National Association of Colleges and Employers (NACE). (2018). Employers want to see these attributes in students' resumes. https://web.archive.org/web/20200524030148/https://www.naceweb.org/ talent-acquisition/candidate-selection/employers-want-to-see-these-attributes-on-students-resumes/

National Communication Association. (2015, November). NCA's Learning Outcomes in Communication. Spectra. https://web.archive.org/web/20200617145106/https://www.natcom.org/sites/default/ files/publications/NCA_Spectra_2015_November.pdf

Ndoye, Al, \& Parker, M. A. (2010). Creating and sustaining a culture of assessment. Planning for Higher Education, 38(2), 28.

Rhodes, T. (2010). Assessing outcomes and improving achievement: Tips and tools for using rubrics. Association of American Colleges and Universities.

Sellnow, D. D., Limperos, A., Frisby, B., Spence, P., Sellnow, T., \& Downs, E. (2015). Expanding the scope of instructional communication research: Looking beyond classroom contexts. Communication Studies, 66, 417-432. https://doi.org/10.1080/10510974.2015.1057750

Spitzberg, B. H. (2007). CSRS the conversational skills rating scale: An instructional assessment of interpersonal competence. In Conversational Skills Rating Scale: An Instructional Assessment of Interpersonal Competence (p. i-53). National Communication Association.

Walvoord, B. (2010). Assessment clear and simple: A practical guide for institutions, departments, and general education (2nd ed.). Jossey-Bass.

Wang, X., \& Hurley, S. (2012). Assessment as a scholarly activity?: Faculty perceptions of and willingness to engage in student learning assessment. Journal of General Education, 61(1), 1-15. https://www. jstor.org/stable/10.5325/jgeneeduc.61.1.0001

Wehlburg, C. (2008). Promoting integrated and transformative assessment: A deeper focus on student learning. Jossey Bass.

Weiner, W. F. (2009). Establishing a culture of assessment. Academe, 95(4), 28-32. https://web.archive. org/web/20200602143931/https://www.aaup.org/article/establishing-culture-assessment

Wergin, J. F. (1999, December). Evaluating department achievements: Consequences for the work of faculty. AAHE Bulletin.

Winne, P. H., \& Azevedo, R. (2014). Metacognition. In R. K. Sawyer (Ed.), Cambridge handbooks in psychology. The Cambridge handbook of the learning sciences (pp. 63-87). Cambridge University Press. https://doi.org/10.1017/CBO9781139519526.006 


\section{APPENDIX \\ Sample WISER Application}

We have provided a sample, very generic, public speaking assignment description that can be modified depending on your program goals.

- An Assignment Description

- The WISER Assessment Measure

- A Corresponding NCA Learning Outcome

- The Oral Communication AAC\&U Value Rubric

- The NCA Competent Speaker Evaluation Form

\section{Assignment Description}

Persuasive speaking can occur in any context. Whether you are persuading someone to think, feel, or do something differently, mediating a discussion or conflict, or pitching a product proposal or campaign, persuasion is necessary. This assignment requires you to convince your listeners to act. The purpose of this assignment is to develop a logical, audience-centered persuasive message and effectively deliver the message in the appropriate context. Your presentation should be research-driven, well-organized, extemporaneous, and include aesthetically appealing visuals. Ultimately, your goal is to persuade and convince your listeners to accept your position or proposal. During your speech, and the preparation leading up to the presentation, you should demonstrate the ability to select an appropriate topic, communicate the specific purpose of the speech; use supporting material effectively; apply an appropriate organizational pattern; use appropriate language; and deliver your presentation in a way that emphasizes competent verbal and non-verbal technique(s).

Potential Contexts Could Include:

- A workplace conflict and persuading others of an appropriate mediation

- The development and implementation of a workplace conflict resolution program

- Using theory-based communication strategies to solve a real-world problem

- Present a proposal or campaign that is client-centric and solves client-based issues

\section{The WISER Assessment Measure}

S: Speak effectively

\section{A Corresponding NCA Learning Outcome}

NCA Learning Outcome (4): Create messages appropriate to the audience, purpose, and context

\section{The Oral Communication AAC\&U Value Rubric}

https://www.aacu.org/value/rubrics/oral-communication 


\section{The NCA Competent Speaker Evaluation Form}

Course:

Semester:

Date:

Project:

Speaker(s):

PRESENTATIONAL COMPETENCIES

RATINGS

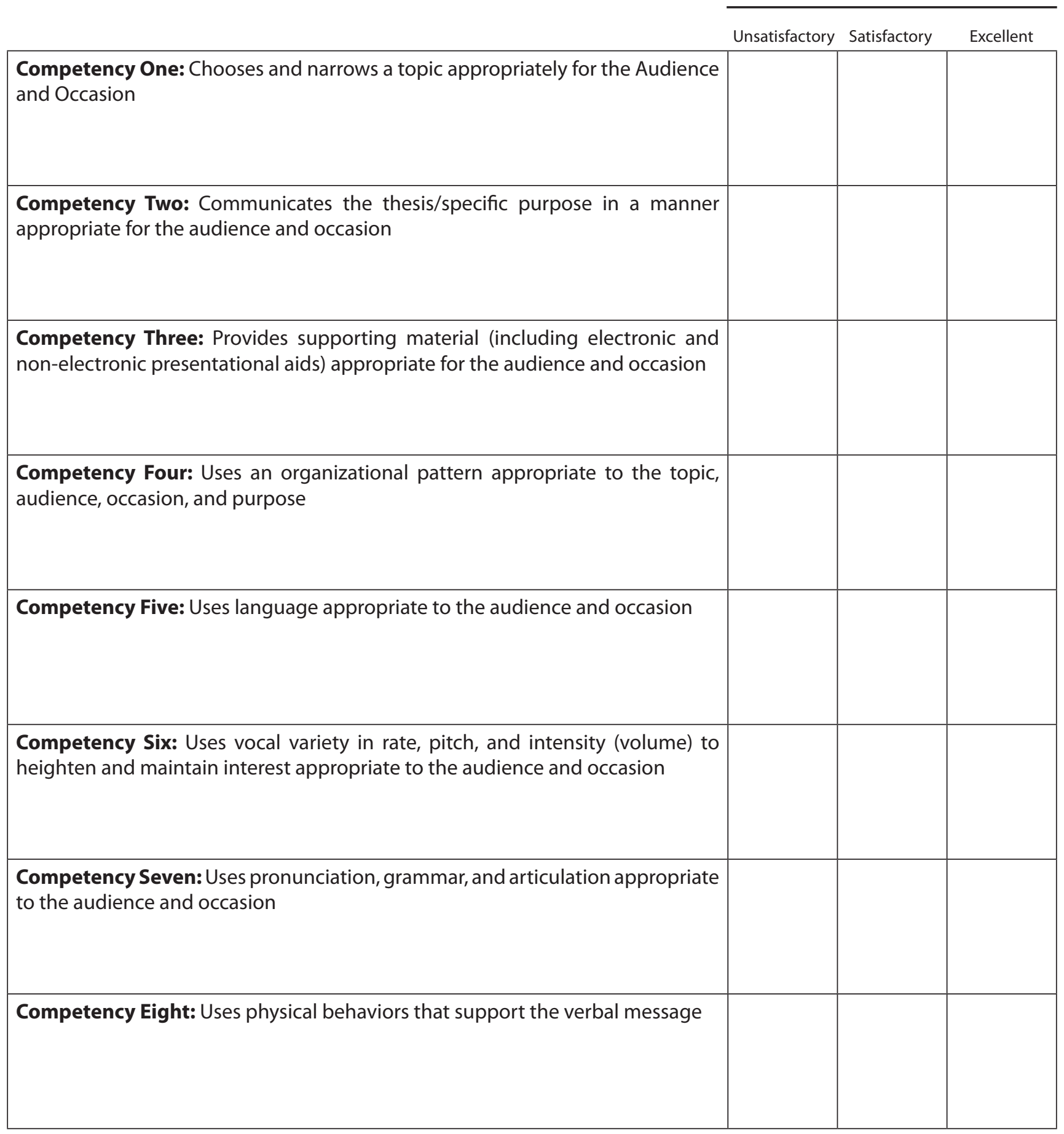

General Comments:

Summative Scores of Eight Competencies: 